\title{
DEVELOPING TRAINING PROGRAMS IN REMOTE SENSING AND GEOSPATIAL APPLICATIONS
}

\author{
VSSN Gopala Krishna Pendyala*1, Vijayan D ${ }^{1}$ \\ ${ }^{1}$ Training and Education Division, ISRO, National Remote Sensing Centre, Balanagar, Hyderabad \\ - (gopalakrishna_pvssn, vijayan_d)@nrsc.gov.in
}

Commission V, WG V/1

KEY WORDS: Remote Sensing and GIS, Capacity building, Training, Components of Training, Feedback, Redesign, Multi-level training

\begin{abstract}
Capacity building programmes of Indian Space Research Organisation (ISRO) are aimed at transfer of technology in the field of Remote Sensing and Geoinformatics for monitoring and sustainable development. ISRO Carries out its capacity building through IIRS, NRSC, SAC, IIST and CSSTEAP. As part of the ISROs' programmes, NRSC is engaged in the capacity building by conducting Regular, Thematic and Customized training courses to enable the effective utilization of Remote Sensing, Geospatial Technologies and its Applications. The main focus of NRSC training programmes is to develop skill sets in usage of these technologies to the efficient and effective development of the country. The target participants for NRSC training programmes are decision makers, implementers and working professionals, who attend short duration courses of 1,2 and 12 weeks. This paper provides information on the training courses conducted by NRSC in the field of Geospatial Applications and also, discuss on the methodology to upgrade these training courses using multi-level approach in meeting user needs/requirements more effectively. The flexibility offered by this method by utilizing the web based and other enabling technologies is discussed.
\end{abstract}

\section{INTRODUCTION}

Space technology through Remote Sensing (RS) and Geographic Information Systems (GIS) has immense potential in decision making process that improves the standards of living of common man in the country. The Remote sensing programme of Indian Space Research Organization (ISRO) is driven by the user needs. Remote Sensing data provides valuable inputs at various levels, to the Government in planning, decision making and executing various projects in sectors such as agriculture, land and water resources, forestry, environment, natural disasters, urban planning, infrastructure development, rural development, and forecasting of potential fishing zones (Website ISRO 2018). A well-knit network called "Natural Resources Management System (NNRMS)" involving Central and State Governments, private sectors, academia and Non-Governmental Organizations is in place for enabling the integration of Remote Sensing, contemporary technologies and conventional practices for management of natural resources (Anup Kumar Sigh, 2015).

National Remote Sensing Centre (NRSC) is carrying out various nationwide application projects utilizing Remote Sensing and Geo-information technology, aimed at benefitting common man at the grass root level. Government of India is encouraging Ministries and stakeholders towards utilization of space technology for achieving the national goal of food, water, energy, infrastructure and environmental securities for which NRSC is identified as focal point. About 150 projects were undertaken with ministries using Space technology in achieving these goals.

\section{CAPACITY BUILDING}

Capacity building, in broader sense can be defined as systematic and integrated approach to develop and continuously improve organizational and individual competences and capabilities necessary for achieving the organizational goals decided from time to time (Ross Holland, 2012, Shaahid Mallick, 2013). Capacity building, under one umbrella consists of four components, mainly (i) Education and Training (ii) Human Resource Development (iii) Knowledge management and (iv) Knowledge networks (Shahid Mallick, 2013).

\subsection{Capacity building in organization perspective}

In the capacity building framework, the organization and the individuals are two important facets. This frame work is shown in figure 1.

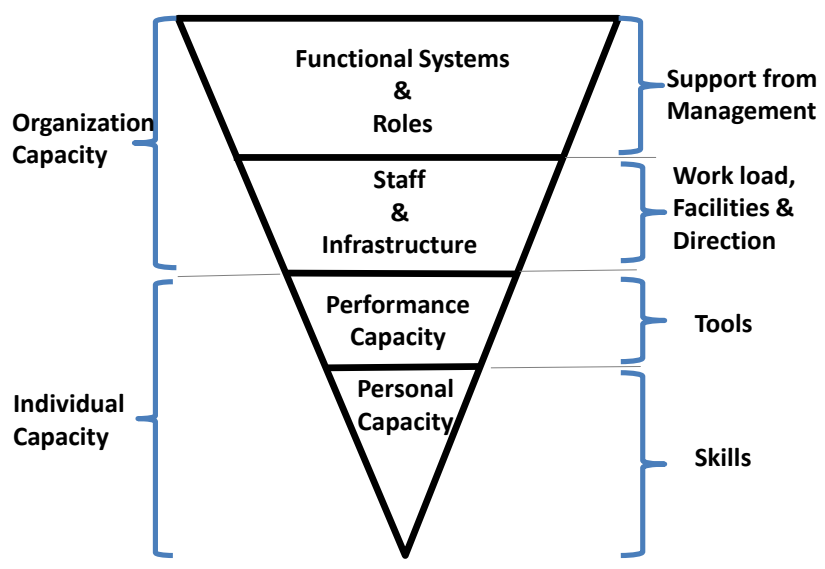

Fig 1. Capacity building frame work of an organization

In the personal capacity, any individual staff gets trained to upgrade the required skills, where in, this training focuses on the familiarization or improvement of skill sets in any particular domain. This knowledge, coupled with the appropriate tools will enhance the performance capacity of that

* Corresponding author 
individual. Individual development together with team capacity, eventually leads to overall performance of the organization. Capacity building support and guidance from management with necessary infrastructure will certainly take the organization to higher levels in the pyramid structure. Hence, Training and Education are key elements under capacity building of any organization, addressing the skill sets of individual stake holders.

\subsection{Training}

Training is a part of capacity building. It is defined as the systematic development of the knowledge, skills and attitude required by an individual to perform adequately a given task or job. As per the Manpower Services Commission, UK, training is "a planned process to modify attitude, knowledge or skill behavior through learning experience to achieve effective performance in an activity or range of activities" (Guide book UNODC). The term performance and training are interrelated.

\subsection{Process of training}

The training process is given as flow chart in figure 2 . The structure of any training course, for a domain, is time variant and continual improvements are done based on the feedback and user requirements. The training course may also be modified, whenever a new tool or method is introduced.

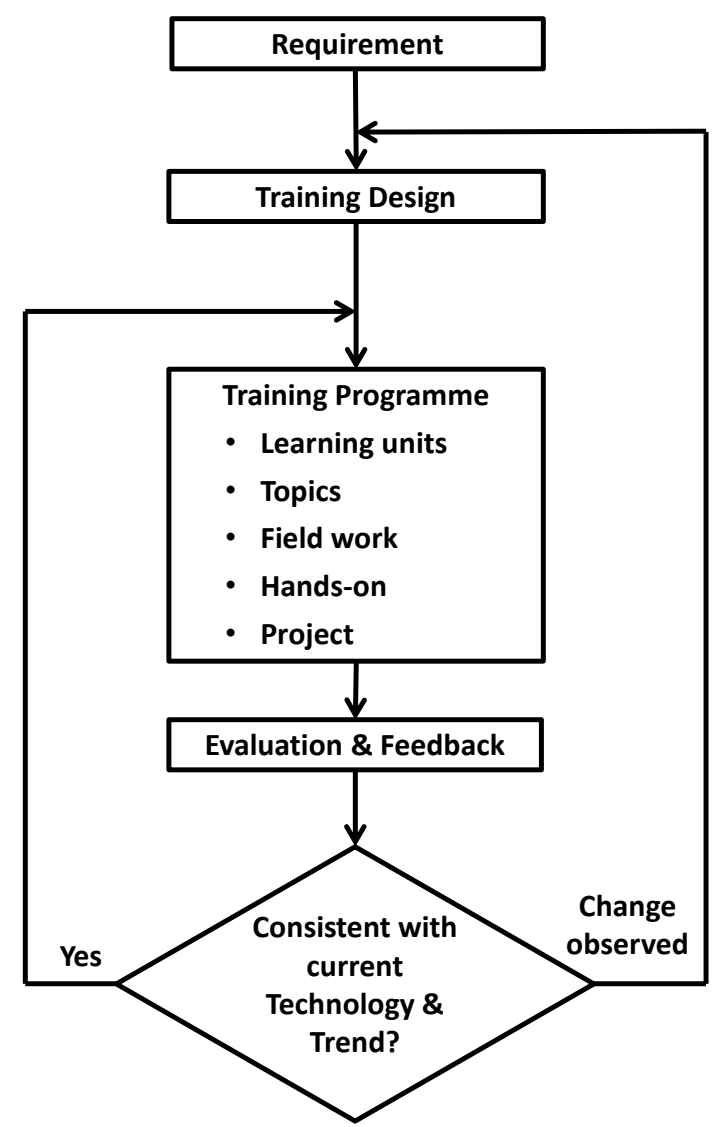

Fig 2. Training process

The current background knowledge and skill level of trainees' in the target group need to be considered while designing a training programme. The objectives, goals and content for an introductory programme to new employees will differ entirely from those for a program generated for experienced trainees learning a new technique (Ross Holland, 2012).

The key elements for the design of any training programme are need assessment, course work design, planning the learning tasks and implementation on practical application/ case study. New topics are introduced to participants through theory lectures to have initial exposure and understanding. Demonstrations will enable them to gain quick assimilation. Practical and case studies related to applications enable the trainees to apply the theoretical knowledge and skills learned on real data. Based on feedback from course participants, gaps would be identified and course design suitably modified.

\section{TRAINING IN RS \& GIS APPLICATIONS}

\subsection{Requirements}

Remote Sensing and GIS technology is an advanced and modern way of dealing with the planning and resource management. There is a wide gap between the requirement and trained professionals in utilizing this technology and deriving useful information. Capacity building through training creates new professionals or upgrades the skills of existing professionals in specific area of applications, to bridge the demand and requirement of trained manpower (Anup Kumar Singh, 2015).

\subsection{Objectives}

The objectives of the training programmes conducted for RS and Geospatial applications are listed below.

1. Build and strengthen knowledge on the special tools related to RS and GIS in efficient functioning and delivery

2. Improve the attitude to create environment in the organization for wide adoption of this technology

3. Design and implement new methods using this technology specific to each domain

4. Impart/transfer knowledge to co staff so that the organization benefits as a whole

5. People can function better at the assigned activities and perform to their fullest potential

The above objectives were arrived at in order to provide quality products, information and deliver services with faster results (Ross Holland, 2012).

\subsection{Levels}

Training planners should consider three levels of staff requirement as given below. The curriculum, method and duration of training vary for each level. To effect the sustainable change, it is necessary to impart training to all levels simultaneously (Ross Holland, 2012).

Level 1: Decision makers, who are responsible for creating the environment needed for improved management

Level 2: Implementers, who are responsible for planning and supervising activities required in the management

Level 3: Working personnel, who are responsible for carrying out the work in the field and lab 


\section{TRAININGS AT NRSC}

\subsection{Capacity building at ISRO level}

The approach of Indian Space Research Organisation (ISRO) to capacity building is to transfer technology through Capacity building and Research in the field of Remote Sensing and Geoinformatics for sustainable development (Senthil Kumar, 2016).

ISRO Carries out its capacity building through its main centers (i) Indian Institute of Remote Sensing (IIRS) (ii) National Remote Sensing Centre (NRSC) (iii) Space Application Centre (SAC) (iv) Indian Institute of Space Science and Technology (IIST) and (v) Centre for Space Science and Technology Education in Asia Pacific (CSSTEAP). The model on which ISRO's Training and effective capacity building works (Senthil Kumar, 2016) is shown in table 1.

\begin{tabular}{|c|c|c|c|c|}
\hline $\begin{array}{l}\text { Sl. } \\
\text { No }\end{array}$ & Type & Execution & Duration & Target \\
\hline 1 & Research & $\begin{array}{c}\text { Guidance, } \\
\text { Funding } \\
\text { support } \\
\text { under } \\
\text { RESPOND }\end{array}$ & $\begin{array}{l}1 \text { to } 2 \\
\text { years }\end{array}$ & $\begin{array}{c}\text { Researchers, } \\
\text { Academia }\end{array}$ \\
\hline 2 & Education & $\begin{array}{l}\text { Masters, } \\
\text { Degree } \\
\text { Diploma, } \\
\text { Certificate, } \\
\text { Tailor-made } \\
\text { Courses }\end{array}$ & $\begin{array}{c}4 \text { weeks } \\
\text { to } 24 \\
\text { months }\end{array}$ & $\begin{array}{c}\text { Students, } \\
\text { Professionals }\end{array}$ \\
\hline 3 & Trainings & $\begin{array}{l}\text { Regular, } \\
\text { Thematic } \\
\text { and } \\
\text { Customized } \\
\text { courses }\end{array}$ & $\begin{array}{l}1 \text { to } 12 \\
\text { weeks }\end{array}$ & $\begin{array}{l}\text { Government, } \\
\text { Private, NGO, } \\
\text { and academia }\end{array}$ \\
\hline 4 & Outreach & $\begin{array}{l}\text { EDUSAT- } \\
\text { DLP, } \\
\text { Partnership } \\
\text { with } \\
\text { Academic } \\
\text { Institutions, } \\
\text { Student } \\
\text { Projects, } \\
\text { School } \\
\text { visits }\end{array}$ & Flexible & $\begin{array}{l}\text { Students and } \\
\text { professionals }\end{array}$ \\
\hline
\end{tabular}

Table 1. ISRO Capacity building (Senthil Kumar, 2016)

\subsection{Training programmes at NRSC}

NRSC is engaged in the capacity building by way of conducting the regular, thematic and Customized training courses to users from Government, PSU, Autonomous, Private Organizations, NGO and Academic Institutions enabling the effective utilization of Space inputs using various Geospatial Technologies and its Applications. It has also established and operationalized 300 systems outreach facility for outreach, outsourcing and student projects etc. This paper focuses on new training design approach that can be adopted by NRSC for improved performance.
The main focus of NRSC training programmes emphasizes on skill based training to develop good understanding in usage of Remote Sensing and Geospatial applications for efficient societal usage. The duration of the courses vary from 2 to 3 days (for decision makers), 1 week (implementers) and 2 and 12 weeks (working professionals). Nearly 20 courses are conducted in a year as shown in figure 3, with 20 to 30 participants in each course (Website NRSC 2018).

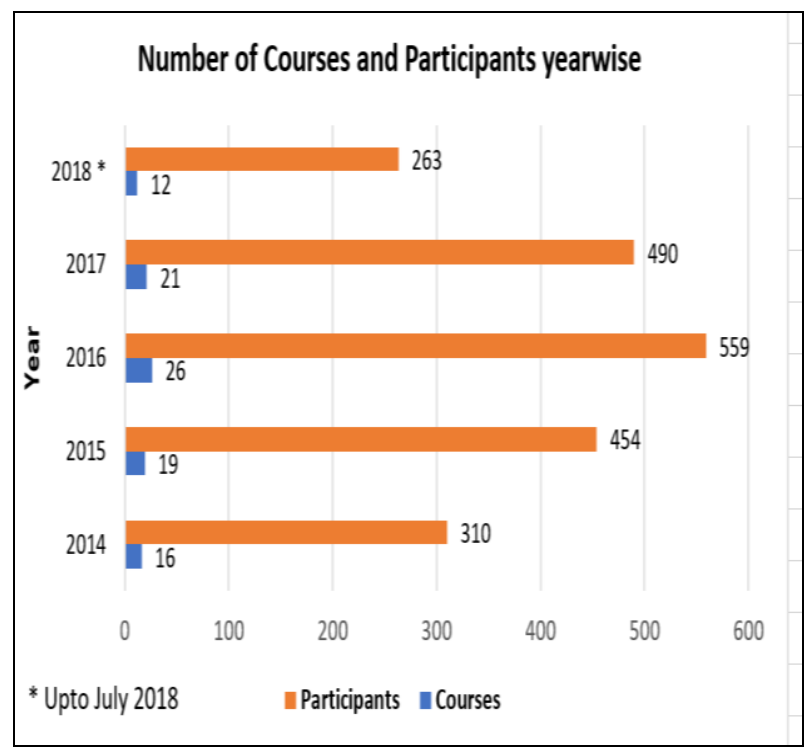

Fig 3. Year wise courses conducted and participants

The training programmes conducted at NRSC are classified into special courses, thematic courses and customized courses.

4.2.1 Special Courses: The special courses of 2 week duration are (i) Hyper spectral Remote Sensing and (ii) Microwave Remote Sensing applications.

The 12 week course on Geospatial technologies and applications provides a comprehensive insight into Remote Sensing, Digital Image Processing, GIS with necessary lab practicals as well as Aerial Remote Sensing including the practical hands on in these disciplines. Various applications such as Agriculture, Soils, Geology, Water Resources, Land Use, Urban studies, Oceanography, Forestry, and Disaster applications etc., are addressed to have full spectrum of understanding of utilization of Geospatial technology with case studies. As part of the training, the hands on project work is allocated in their respective specialized area to independently work with the guidance of resource experts.

4.2.2 Thematic courses: Theme based courses provide indepth knowledge in a particular domain. Courses such as (i) Geospatial technologies for Land resources management, (ii) Geospatial technologies for Climate studies, (iii) Remote sensing for Geological applications and (iv) Large Scale Mapping for City/Urban planning and Panchayat Raj applications are very popular with user community, faculty and research scholar from academia. 
4.2.3 Customized courses: These courses are aimed at providing knowledge and operational skills to meet the objectives of user organizations. Based upon the background of participants and field of interest, the courses are designed to provide in depth understanding of theory and practical exposure to facilitate to carry out the operational or research projects in their respective departments. Courses for Indian Bureau of Mines, Coal India were conducted in the year 2017. The National Hydrology Project course on water resources is being conducted four times in a year since 2017 and will be organized till 2024.

\subsection{Training structure}

The four essential components of any training programme are

1. Exposure to theory and concepts

2. Field work to collect ground truth

3. Demonstrations on any particular topic and

4. Hands on / Practical

Every course is designed to contain all the four components by addressing the concepts, methods, practice, collection of input data and case studies. The duration of these components vary in proportion depending on the duration and target participants. The theory part is more for the decision makers whereas the demonstrations and practical are more for the working personnel. The proportionate shares of these components in each course are shown in figure 4.

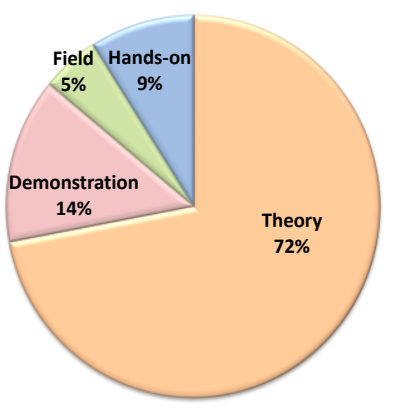

(a) 3 day course

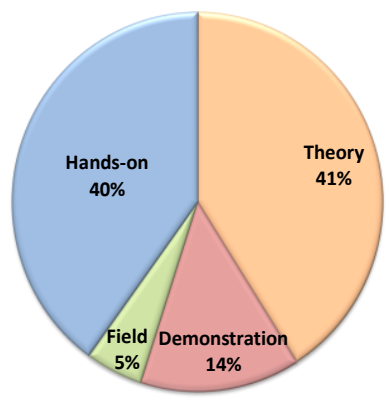

(c) 2 week course

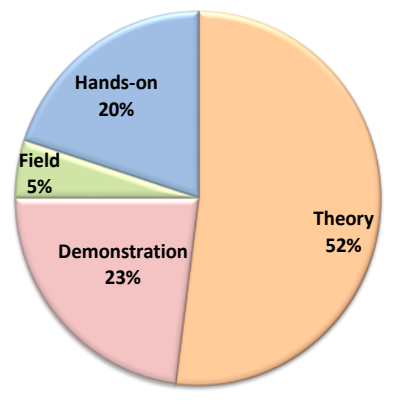

(b) 1 week course

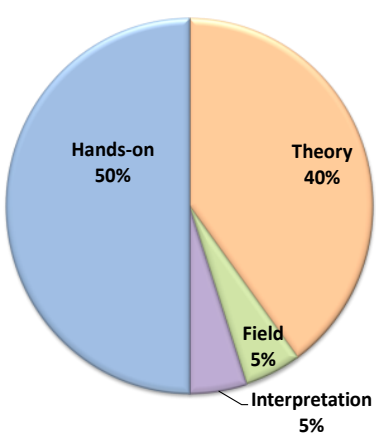

(d) 12 week course
Fig 4. Share of training components

\subsection{Feedback}

The feedback received from the participants at the end of each course was analyzed for incorporating improvements in the forthcoming courses. The previous year feedback (2017) for 18 courses was consolidated and the following suggestions emerged (Anjum Mahtab, 2017):

1. Increase course duration

2. Increase hands on time duration

3. More time to be given for field work

4. Improvements to be made in the course material

5. Introduce mini projects for end to end exposure in handling/ processing of data

\section{REDESIGN OF RS AND GEOSPATIAL APPLICATIONS COURSES}

Based on the feedback in 4.4 , it is imperative that some improvements to the existing structure of training course based on these suggestions is required. This will enable the participant's learning and development process in more effective manner. Hence, the training method and its components of the training are revisited. Changes that can be brought to the existing course design is discussed subsequently.

\subsection{Constraints}

It is required to consider the following constraints while designing the new course or modifying the existing course to meet the feedback suggestions listed in 4.4.

1. Heterogeneity of trainees' background

2. Trainees need to have domain knowledge for getting trained in specialized fields

3. Availability of time for trainees to attend long duration courses due to pressing commitments

4. The domains are unique, having limited experts as faculty

5. Collection of field data in near real time in synchronization with satellite pass as needed for specific applications

6. Cost and complexity of the specific software imposes constraints on bulk procurement for training

\subsection{Multi-level training approach}

While considering the constraints stated above, it is essential that the training courses should be flexible in duration and also should be modular, as well as offer learning from the work place without physically attending the class room. This will save the time of experts as well as trainees and also offer the trainees an opportunity to learn in their own working environment.

Figure 5 shows the proposed new approach of training in RS and Geospatial technology applications by utilizing the concept of multilevel training approach (Steve W J Kozlowski et al., 2000). This model has been modified to suit RS and Geospatial training requirement by dividing the entire training programme into 6 levels (Module $0-5$ ). 


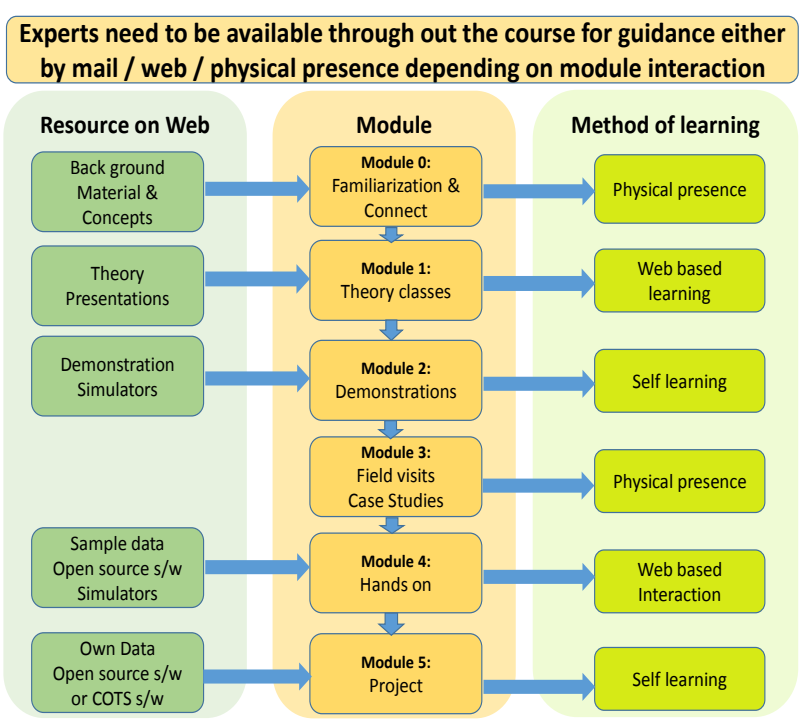

Fig 5. Multi-level training implementation plan

Out of 6 modules, the Module 0 and Module 3 need to be carried out in the physical presence of expert. Besides the initial interaction and familiarisation, the trainee is trained on the field instruments and data collection methods. The success of this approach lies in utilising the web based technologies. General resources, presentations, simulators, open source software and data need to be kept under open access website. Tutorials and demonstrations are offered by web based applications (webinars/ Skype/ Simulators). For hands on and project, the resources will be available at trainees' site and expert guidance will be available through email or web based contact.

This training approach takes care of most of the constraints listed under 5.1 as well as satisfying the feedback suggestions under 4.4. The complexity and allocation of time for each module is based on the level of the staff trained. The trainer is virtually available to all trainees through web based contact and will be maintaining one to many relationship.

Based on feedback from course participants, improvements should be made to the respective module in successive courses as mentioned in Figure 2.

\subsection{Essential requirements}

The functioning of this multilevel approach will be effective by addressing the following:

5.3.1 Open Geospatial resources: Even though, there are lot of Geospatial Resources available on the internet, it is required to be suitably organised as per the training requirement (Christopher potter et al. 2004). Open source software resources for image processing, photogrammetry, mapping, GIS besides Microwave and Hyper spectral data analysis needs to be tapped and utilized. It is very much essential that, the training institutes such as IIRS, NRSC should place the required back ground material as well as the presentations in open access, so that the trainees can read the material well before they come for training. This will enable all the trainees in a programme to acquire the essential background knowledge and be at the same platform when the training starts.
5.3.2 E learning and web based material: Though certain number of online courses, modules and apps are available, they are addressing only the core/basic aspects of RS and GIS. However, e-learning modules with state of art illustrations needs to be developed in the fields of land use, land resource management, agriculture, forestry, climate studies, geology, water resources etc., which shall provide in-depth focus on the domain specific needs.

5.3.3 Hands on exposure by simulators: Simulators for practical modules to support hands on exposure are required at trainee's end. This ensures overcoming the constraints such as expert trainers, lab resources and processing software since the trainees can work on their own systems at their work places.

5.3.4 SOP and guides for field data collection: As remote sensing applications totally rely on field data/ ground measurements. A large number of field data collection and interpretation methods are to be provided in the form of Standard Operating Procedures (SOPs) and theses hand-outs be given to trainees during the contact session about field data collection.

5.3.5 Industry participation: To support skill development at user sites on specific domains that use commercial off-theshelf (COTS) software industries, should be associated to impart training on their software. This will enable faster technology outreach, providing expertise sharing and promoting their software by which gain mutual benefit.

\section{CONCLUSIONS}

Online and e-learning modules are available for basic courses on Remote Sensing and GIS. The skill based technology courses and domain specific Geospatial application courses have constraints in the form of availability of experts, limited time availability for trainees. These constraints can be overcome to a greater extent by adopting Multi-level training approach combined with internet based technologies. The training can be carried out having sequential modules in multiple levels by way of offline guided learning combined with contact programmes.

\section{ACKNOWLEDGEMENTS}

The authors acknowledge the support and guidance provided by Shri Santanu Chowdhury, Director, NRSC. The contribution from the staff of Training \& Education Division, NRSC and the contributions of all the resource scientists of other areas of NRSC in successful conduct of courses also is duly acknowledged. The authors also acknowledge the contributions of Dr. M V R Sesha Sai and Dr. Rajashree V Bothale, for providing valuable suggestions for improvements.

\section{REFERENCES}

Anjum Mahtab., 2017. A document on the Feedback Analysis of the Training Courses conducted by Training \& Education Division, NRSC. Internal report of NRSC.

Anupam Kumar Singh., 2015. Remote Sensing and GIS Techniques in India: A synergetic approach towards sustainable natural resource management. International conference for Sustainability- Engineering Information Technology, Management and Environment Faridabad. 
Christopher Potter, Richard Brough., 2004. Systematic capacity Building: A hierarchy needs. From the book Health Policy and Planning, Oxford University press, DOI:10.1093/heapol/czh038.

Jianya Gong, Peng Yue, Tsehaie Woldai, Fuan Tsai, Huayi Wu, Armin Gruen, Le Wang, Idor Musikhin., 2017. Geoinformatics Education and Outreach: Looking Forward. Geospatial Information Science, 20:2, 209-217, DOI: $10.1080 / 10095020.2017 .1337319$

Internet resource: Systematic approach to training (Chapter 2) from the book Guide for trainers published by Regional Precursor project for SAARC countries United Nations Office on Drugs and crime.

Internet resource: https://www.nrsc.gov.in, 2018.

Internet resource: https://www.isro.gov.in/applications, 2018.

Senthil Kumar.A., 2016. Capacity Building Activities in Earth Observation at ISRO. Presentation at Committee on Earth Observation Satellites (CEOS).

Shahid Mallick., 2013. Capacity Building: Concept, definition and Methodology for self-assessment. Presentation at Human Resources Roadmap and Capacity Building.

Steve W J Kozlowski, Kenneth G Brown, Daniel A Weissbein, Janis Cannon-Bowers, Eduardo Salas., 2000, A multilevel approach to training effectiveness: Enhancing horizontal and vertical transfer (Chapter 4). Book A multi-Level Approach to Theory and Research in Organizations, Jossey- Bass. 